\title{
Hybridization and Cutting of Buddleja Genus
}

\author{
Jialin Zhang \\ Kunming Institute of Botany, Chinese Academy of Science, Kunming, China
}

\begin{abstract}
Buddleia davidii, also known as butterfly bush, is a unique species in China, with extensive cultivation and promotion values. The purpose of cross-breeding is to promote environmental adaptation and improve its economic benefits as a garden plant.. As Buddleja is asexual, cutting can aid in mass production of the hybrid offspring, thus stabilising local ecosystem.
\end{abstract}

\section{Introduction}

Buddlejoideae, under the family of Scrophulariaceae, is a widely cultivated and extremely popular flowering shrub with attractive foliage, diverse colours and strong aroma. As a member of Buddlejaceae, the genus Buddleja has about 100-150 subspecies (e.g. Buddleja davidii, $B$. lindleyana, $B$. japonica, $B . \times$ weyeriana) that is distributed in north andsouth America, south and east Africa, as well as south-central and southeast Asia (Sandra B. Wilson et al. 2004). There are about 100 species in the world and about 23 species in Asia, of which 21 species are distributed in China (Chen et al., 2007). Out of these species, B. davidii Franchet is the most common.

B. (Synonyms. Buddleia davidii; also known as butterfly bush) is a perennial, semi-deciduous, multistemmed shrub that readily establishes in disturbed areas of temperate, subtropical, and tropical climates. Native to central and southwestern China, it could reach up to 3,500 meters above sea level. (Tallent-Halsell \& Watt, 2009).

B. davidii has been introduced to the Americas, Australia, Europe, and New Zealand as an ornamental for its fragrant and showy flowers. It is a widely cultivated as a popular garden plant for its economic values to the horticultural industry. Certain B. davidii cultivars are worth over $\$ 200,000 /$ year to plant growers in Georgia, USA, (Tallent-Halsell \& Watt, 2009). In addition to the aesthetic and fragrant appearance of $B$. davidii, the flowering shrub has been closely related to butterflies, moths, and hummingbirds (Laere et al. 2009). There are also certain species of Buddleja which have been used as folk medicine for a variety of illnesses for centuries. In addition, the leaves of some species of Buddleja have been used for centuries for fishing in China as they have proven detrimental to the fish (Tallent-Halsell \& Watt, 2009). W

However, many countries having introduced $B$. start to consider it as invasive and problematic. There are concerns that it has potential negative and irreversible impacts on local agriculture and wild lands (TallentHalsell \& Watt, 2009).

The use of native plants as ornamental would help avoid invasions from exotic species. The local ecosystem of China as a whole consists of biocenosis and the environment they live in, which could adjust and organize itself to maintain balance through adaptation and development. Failures of introduced species to adapt to the local ecosystem and potential unrestricted growth factors may eventually threaten other species, breaking down balance of the local ecosystem(Shi \& Liu, 2013).

\section{Aim of the research}

The idea of using native plant is important. Therefore, Buddleia davidii, as a local species of China, is worth promoting. The paper also I focused on cross-breeding of this genus and asexual reproduction through hybridization and cutting.

The purpose of cross breeding aims at facilitating the adaption to the external environment and improve its economic benefits as a garden plant by perfecting its appearance. Cutting can help mass-produce hybridization as it is asexual, thus stabilising the local ecosystem.

\section{The previous research and development of the breeding and cutting of Buddleja genus:}

\section{Breeding:}

Starting as early as 1920, Buddleja davidii breeding programs have been focusing on the scale of breeding and diverse colours under harsh conditions for plantation (Tallent-Halsell \& Watt, 2009). Meanwhile, the hybridization programs are concentrating on the traits of flower colours, inflorescence morphology, compact growth habits and grey pubescent foliage.

These breeding programs generally include intergeneric hybridization, physical breeding, bioengineering, and chemical breeding.

\footnotetext{
${ }^{*}$ Corresponding author: zhangcjialin@gmail.com
} 
Firstly, in terms of intergeneric hybridization, W. van de Weyer developed interspecific hybrids in 1920 from crosses between $B$. globosa and B. magnifica, which was classified as $B$. × weyeriana and generally characterized by followers with colours between yellow and orange in interrupted patterns along the inflorescence length. (Tallent-Halsell \& Watt, 2009). Another hybrid was discovered by Raymond Moore in 1949 between diploid B. madagascarensis Lam. and the diploid B. crispa. Hybrids from this intersectional cross resulted in polypanicles of dense orange flowers that retained the indehiscent fruit characteristic. In addition, a controlled cross between $B$. davidii var. nanhoensis (Chitt.) Rehd. 'Nanho Purple' and B. lindleyana Fort. ex Lindl. in 2004 produced a hybrid exhibiting characteristics of both parents as well as a number of intermediate traits. Flowers tend to be larger than either parent with an extended blooming period. The hybrid grows better at lower temperatures with fewer leaves dropped in winter and more flowers in blossom (Dunn \& Lindstrom, 2007)

Secondly, gamma radiation has been introduced in University of Georgia as a physical breeding technique to induce sterility in $B$. davidii cultivars (Tallent-Halsell \& Watt, 2009).

Thirdly, bioengineering has played a significant role in breeding development. Researchers used genetic engineering techniques to create hybrids with dwarf or non-functional reproductive organs or heavier seeds that are not carried by the wind. In addition, Lindstrom have sought to reduce potential invasions by producing hybrid varieties that either alter plant morphology or have an odd ploidy number (Tallent-Halsell \& Watt, 2009). Introgression of flower colour in $B$. davidii is made possible by polyploidisation and interspecific hybridisation. There was an interspecific breeding programme with $B$. globose that introduced yellow in the commercial B. davidii assortment through introgression.
Interspecific crosses between chromosome doubled $B$. globosa genotypes and $B$. davidii produced a progeny with yellow flower colour resembling $B$. davidii, which offers new opportunities for Buddleja breeding programmes (Laere et al., 2011).

Finally, for chemical breeding, a study in 2007 determined that oryzalin could be used to restore fertility and alter morphological traits such as flower size or growth habit of other Buddleja species as longer and more intense exposure could lead to greater chromosome doubling potential (Dunn \& Lindstrom, 2007)

\section{Cutting:}

There are a number of cutting programs of Buddleja in China.

Liu et al. (2008) conducted orthogonal experiments on cutting propagation of four $B$. davidii breeding lines. The result showed that all the four lines belonged to the lenticel rooting family. In the two media, the soil mixture composed of clay and sand in equal proportion + perlite had a positive effect on rooting rate while peat soil + perlite had a positive effect on rooting number. The study shows that the root number is positively correlated with rooting length.

$\mathrm{Xu}$ (2015) investigated three substrates and two rooting agents, and carried out cutting experiments on $B$. davidii by random combination. The results showed Peat soil: sand (1:1) matrix and Guoguang rooting agent works more effectively for cuttings breeding of $B$. davidii.

Zhang et al. (2017) studied the suitable cutting matrix of Buddleja by experimenting with different ratios of vermiculite, perlite, sand and soil. The results showed that the strong permeability of sand is beneficial to the growth of root elongation due to strong permeability of perlite and strong water conservation in soil. The combination of the two can increase the number of rooting and maintain moisture to increase the survival rate.

\section{Research Hypothesis}

\section{- Hybridization of Buddleja}
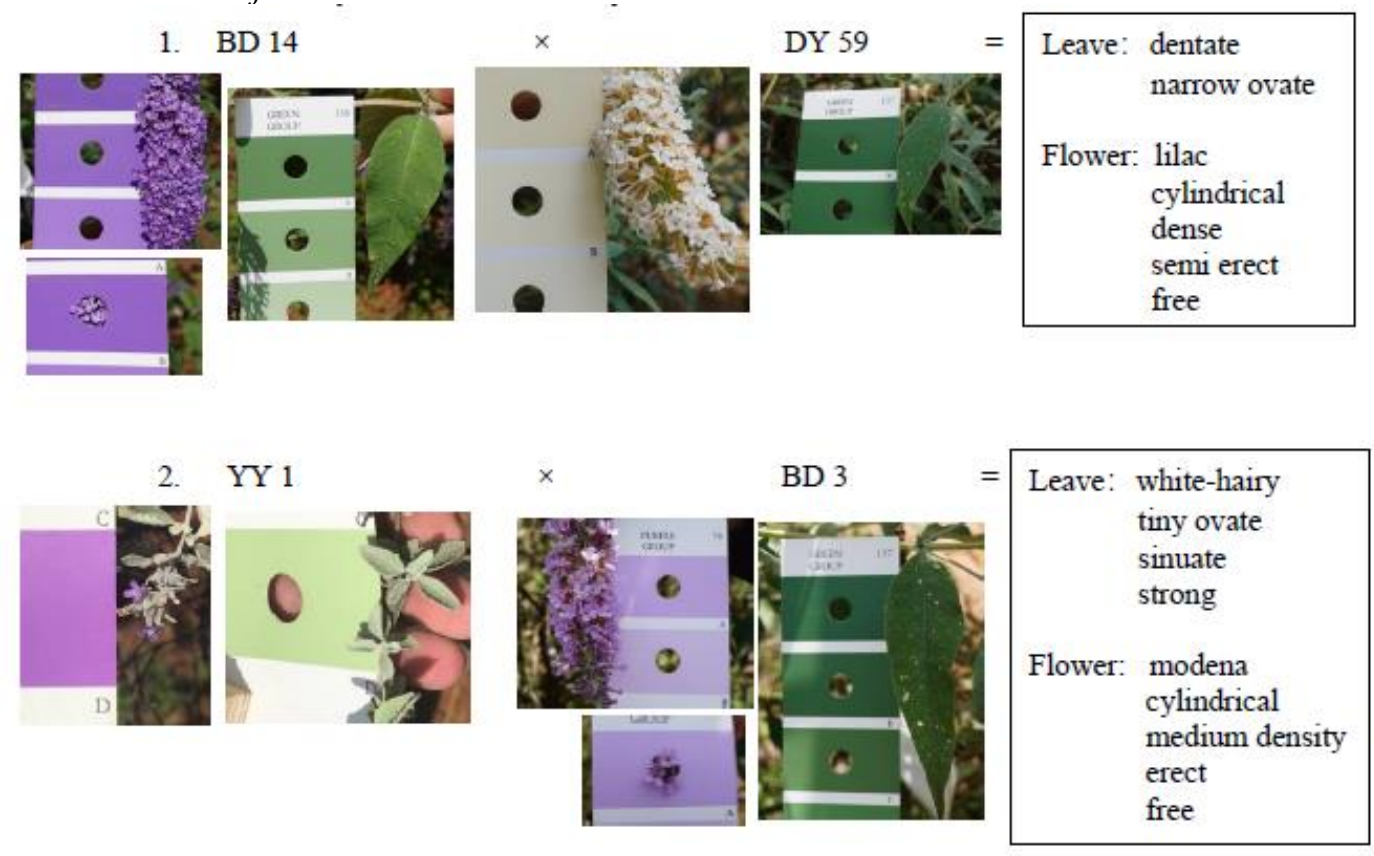

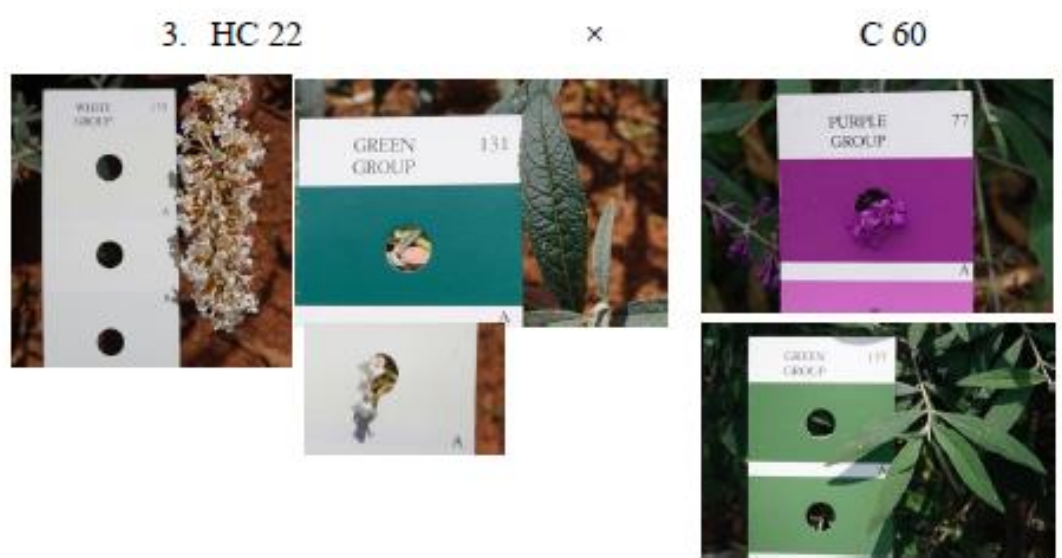

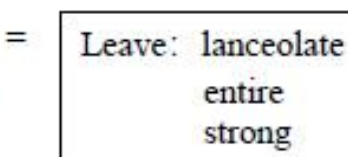

Flower: lilac conical sparse horizontal free

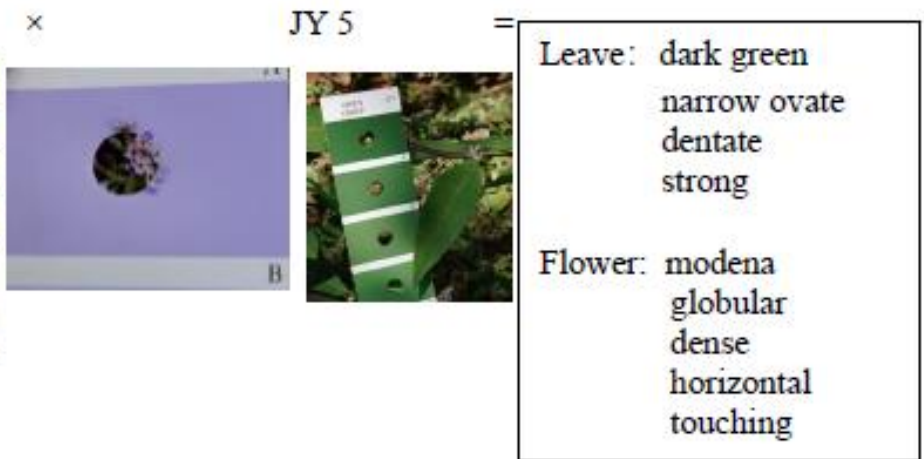

5. BA 2

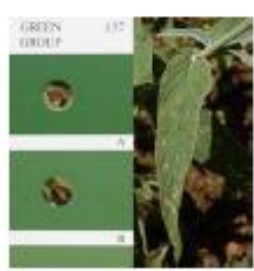

$\times$

DY 54

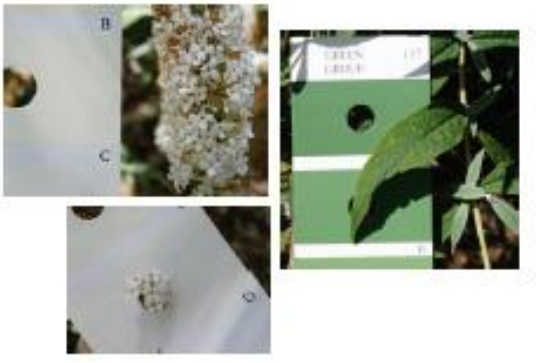

Leave: lanceolate white-hairy entire

Flower: yellow small globular medium density horizontal free

\section{6. $\mathrm{MX} 8$}

$\times$

BD $14=$
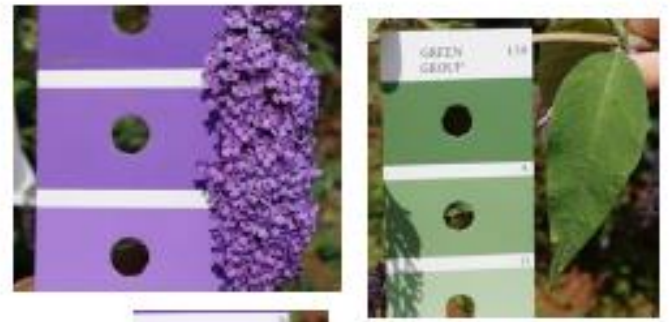

Leave: white-hairy narrow ovate entire

Flower: modena white-hairy conical dense free 
7. $\mathrm{HC} 5$

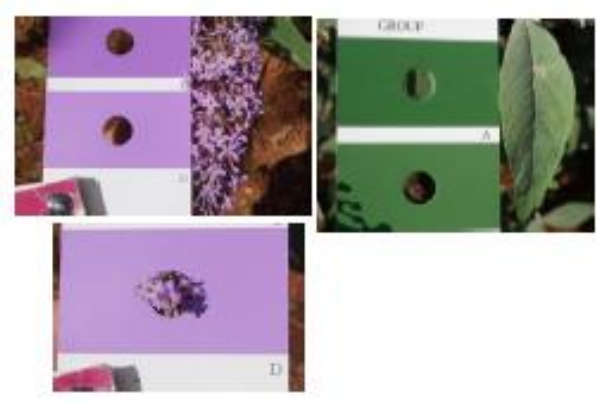

8. DY 54

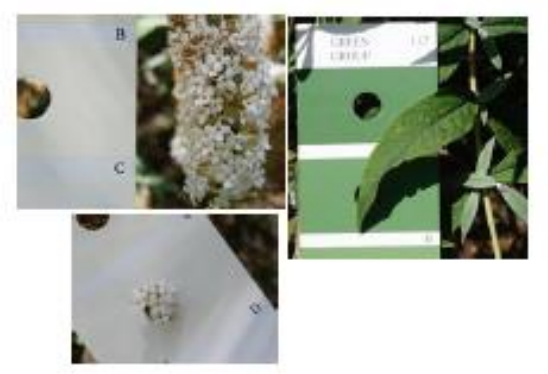

9. DY 52

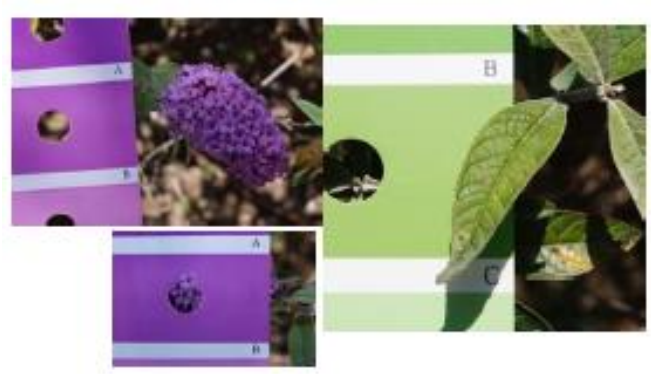

10. BA 2

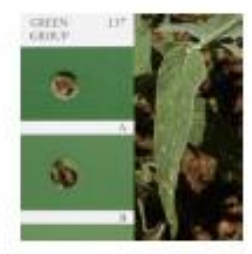

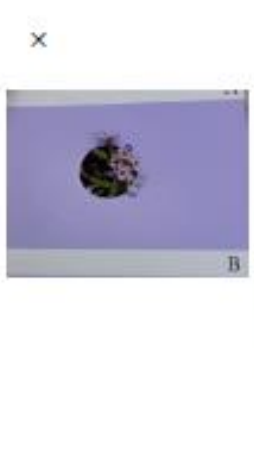
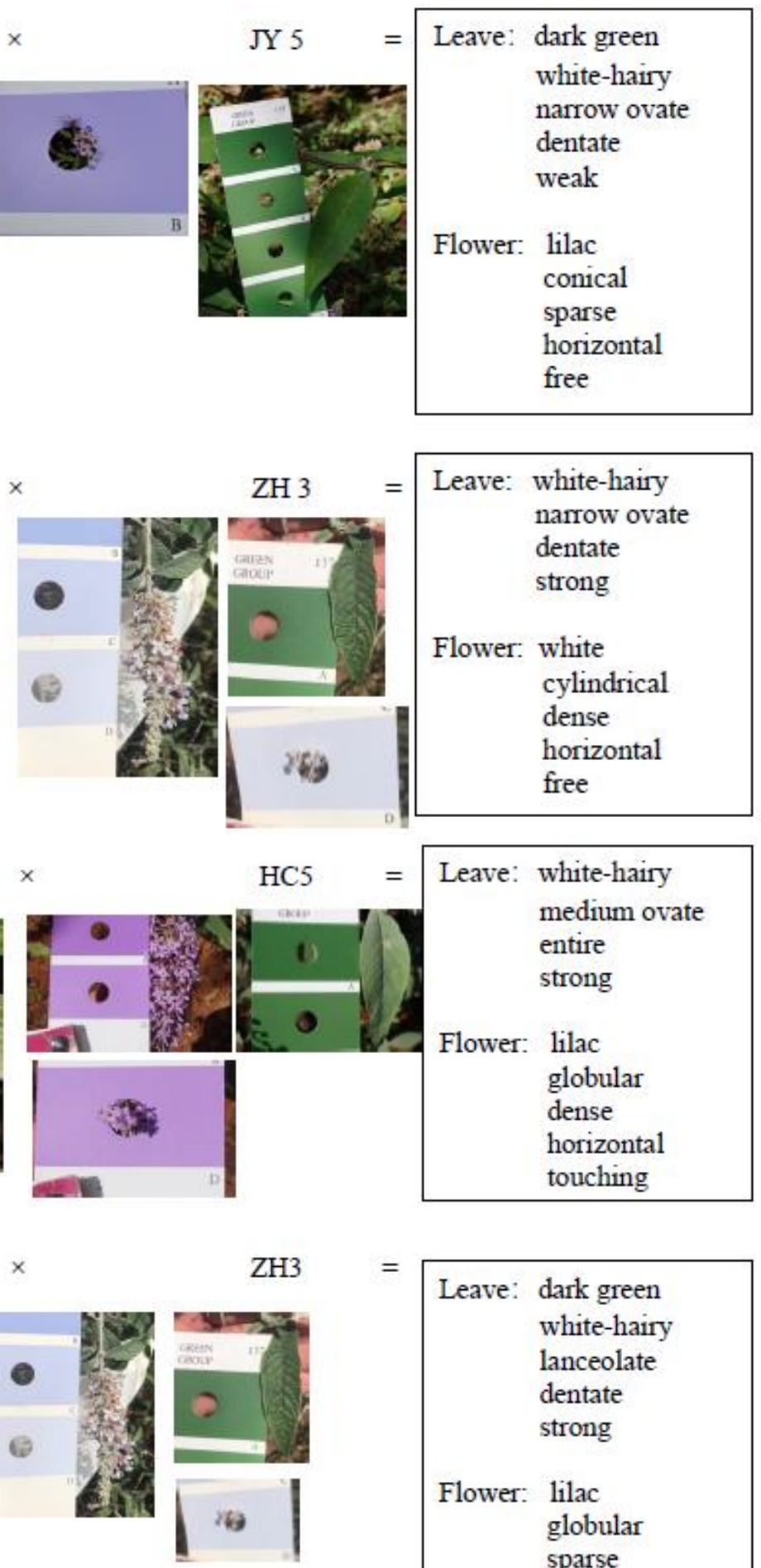

\begin{tabular}{|cl|}
\hline Leave: & dark green \\
& white-hairy \\
& lanceolate \\
& dentate \\
strong & \\
Flower: & lilac \\
& globular \\
sparse \\
semi erect \\
free
\end{tabular}


11. BA 2

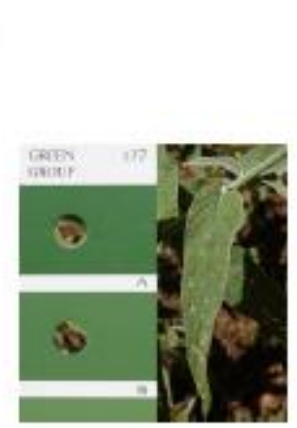

MX9

\begin{tabular}{|c|c|}
\hline Leave: & $\begin{array}{l}\text { white-hairy } \\
\text { lanceolate } \\
\text { dentate }\end{array}$ \\
\hline Flower: & $\begin{array}{l}\text { white-hairy } \\
\text { yellow } \\
\text { globular } \\
\text { dense } \\
\text { free }\end{array}$ \\
\hline
\end{tabular}

12. BA 2
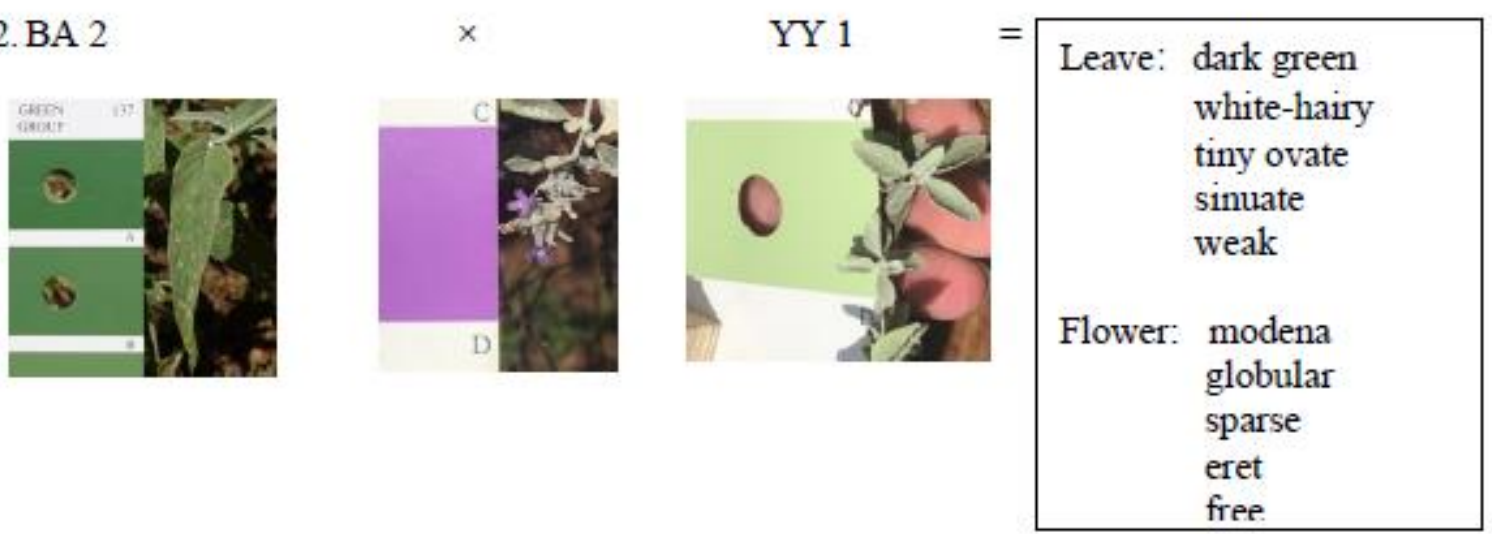

13. YY 1
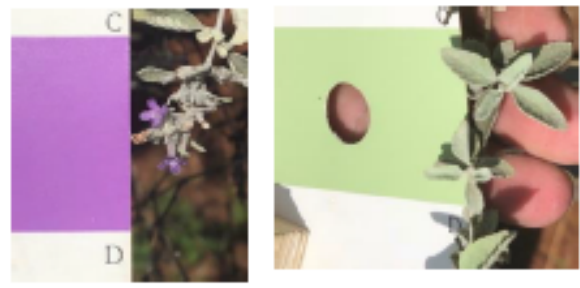

- Cutting of 5 different F1 hybrids of Buddleja

\section{Research plan and schedule}

\begin{tabular}{c|cccc} 
WORK LIST & WEEK & WEEK & WEEK & WEEK \\
& $\mathbf{1}$ & $\mathbf{2}$ & $\mathbf{3}$ & $\mathbf{4}$ \\
\hline THESIS & $\checkmark$ & $\checkmark$ & & \\
PROPOSAL & & & & \\
TEST THE RHS & $\checkmark$ & & & \\
COLOUR & & & & \\
VALUE & & & & \\
MEASURING & $\checkmark$ & & \\
PUTTING ON & $\checkmark$ & & $\checkmark$ \\
BAGS & & & $\checkmark$ & $\checkmark$ \\
POLLINATION & & $\checkmark$ &
\end{tabular}

THESIS

PROPOSAL

$=$\begin{tabular}{cl|}
\hline Leave: & white-hairy \\
& $\begin{array}{l}\text { lanceolate } \\
\text { sinuate }\end{array}$ \\
Flower: & yellow \\
& conical \\
sparse \\
eret \\
free
\end{tabular}

\section{Result Predictions}

- $65 \%$ of these pollinated ovaries will expand

- Collect seeds from this batch of hybrids

- Obtain 50\% seedlings from the cuttings

\section{Results}

- By August 22, 2018, 62\% of these pollinated ovaries expanded. 


\begin{tabular}{|c|c|c|c|c|c|c|c|c|}
\hline DATE & $\begin{array}{l}\text { FEMALE } \\
\text { PARENT }\end{array}$ & $\begin{array}{l}\text { MALE } \\
\text { PARENT }\end{array}$ & NO. & MARK & COMMENTS & $\begin{array}{c}\text { SECCE } \\
\text { D OR } \\
\text { NOT }\end{array}$ & $\begin{array}{c}\text { FERTIL } \\
\text { ISED } \\
\text { OVAR } \\
\text { Y NO. }\end{array}$ & $\begin{array}{l}\text { PERCENT } \\
\text { AGE } \%\end{array}$ \\
\hline $24 / 07 / 2018$ & BD 3 & YY 1 & 60 & & & yes & 12 & 20 \\
\hline $24 / 07 / 2018$ & DY 54 & BA 2 & 48 & & & no & 0 & 0 \\
\hline $24 / 07 / 2018$ & $\mathrm{ZH} 3$ & BA 2 & 13 & & & no & 0 & 0 \\
\hline $24 / 07 / 2018$ & ZH 3 & BA 2 & 9 & & & no & 0 & 0 \\
\hline $24 / 07 / 2018$ & YY 1 & BA 2 & 1 & & & no & 0 & 0 \\
\hline $24 / 07 / 2018$ & YY 1 & BA 2 & 1 & & & no & 0 & 0 \\
\hline $24 / 07 / 2018$ & MX 9 & BA 2 & 3 & & & yes & 2 & 7 \\
\hline $24 / 07 / 2018$ & YY 1 & MX 8 & 1 & & & no & 0 & 0 \\
\hline $25 / 07 / 2018$ & ZH 3 & DY54 & 26 & & raining & yes & 20 & 77 \\
\hline $26 / 07 / 2018$ & BD14 & DY59 & 185 & & DY 59 little pollen & no & & \\
\hline $26 / 07 / 2018$ & MX 8 & BD14 & 4 & & & yes & 3 & 75 \\
\hline $26 / 07 / 2018$ & MX 8 & BD14 & 5 & & & yes & 2 & 40 \\
\hline $26 / 07 / 2018$ & C 60 & $\mathrm{HC} 22$ & 25 & green & $\begin{array}{c}\text { HC } 22 \text { the flowering time } \\
\text { has passed }\end{array}$ & yes & 23 & 93 \\
\hline $26 / 07 / 2018$ & HC 22 & C60 & 5 & green & $\begin{array}{c}\text { HC } 22 \text { the flowers are } \\
\text { small }\end{array}$ & yes & 1 & 20 \\
\hline $26 / 07 / 2018$ & JY 5 & DY 52 & 23 & green & & & & \\
\hline $26 / 07 / 2018$ & DY 52 & JY 5 & 15 & green & & yes & 14 & 93 \\
\hline $26 / 07 / 2018$ & HC 5 & DY 52 & 15 & green & & yes & 13 & 87 \\
\hline $26 / 07 / 2018$ & DY 52 & HC 5 & 27 & green & & yes & 23 & 85 \\
\hline $26 / 07 / 2018$ & HC 5 & JY 5 & 21 & red & & yes & 15 & 71 \\
\hline $26 / 07 / 2018$ & JY 5 & $\mathrm{HC} 5$ & 26 & red & & & & \\
\hline $27 / 07 / 2018$ & MX 8 & BD 3 & 3 & green & $\begin{array}{l}\text { MX } 8 \text { little inflorescence } \\
\text { and the flowers are small }\end{array}$ & yes & 1 & 30 \\
\hline $27 / 07 / 2018$ & DY 54 & BD 3 & 22 & & DY 54 many insects & yes & 20 & 90 \\
\hline $27 / 07 / 2018$ & $\mathrm{ZH} 3$ & BD 3 & 6 & & & yes & 4 & 66 \\
\hline $27 / 07 / 2018$ & C 60 & BD 3 & 35 & green & & yes & 35 & 100 \\
\hline $27 / 07 / 2018$ & MX 8 & ZH 3 & 8 & green & ZH 3 little pollen & yes & 6 & 75 \\
\hline $27 / 07 / 2018$ & YY 1 & ZH 3 & 1 & red & ZH 3 little pollen & no & 0 & 0 \\
\hline $27 / 07 / 2018$ & YY 1 & ZH 3 & 2 & red & ZH 3 little pollen & no & 0 & 0 \\
\hline $27 / 07 / 2018$ & C 60 & ZH 3 & 26 & green & ZH 3 little pollen & yes & 26 & 100 \\
\hline $27 / 07 / 2018$ & $\mathrm{ZH} 3$ & DY 54 & 14 & red & & yes & 13 & 93 \\
\hline $27 / 07 / 2018$ & MX 8 & DY 54 & 13 & red & & yes & 11 & 85 \\
\hline $27 / 07 / 2018$ & C 60 & MX 8 & 24 & red & & yes & 23 & 96 \\
\hline & & & 433 & & & & 267 & 62 \\
\hline
\end{tabular}

\section{Conclusion}

The table of results shows that as of August 22, 2018, 62\% of the pollinated ovaries had expanded, as expanded. However, weather conditions and unavoidable states of the flowers could hinder pollination. Therefore, Buddleja is likely to expand further in more parts of China. This process of crossbreeding could facilitate Buddleja's adaption to the environment and boost its economic use as a garden plant, thus stabilising the local ecosystem.

\section{References}

1. Chen, G., Sun, W., and Sun, H. "Ploidy variation in Buddleja L. (Buddlejaceae) in the Sino-Himalayan region and its biogeographical
implications."Botanical Journal of the Linnean Society 154.3(2010):305-312.

2. Dunn, B. L., and Lindstrom, J. T. "Oryzalin-induced chromosome doubling in Buddleja to facilitate interspecific hybridization. "Hortscience A Publication of the American Society for Horticultural Science42.194(2007):1326-1328.

3. Laere, K. V., Huylenbroeck, J. V., and Bockstaele, E. $\mathrm{V}$. "Introgression of yellow flower colour in Buddleja davidii by means of polyploidisation and interspecific hybridisation. "Horticultural Science38.3(2011):96-103.

4. Laere, K. V., Leus, L., Huylenbreck, J. V., et al. "Interspecific hybridisation and genome size analysis in Buddleja. "Euphytica166.3(2009):445-456.

5. Li, P.T., Leeuwenberg, A. J. M., and Middleton, D. J. "Myrsinaceae through Loganiaceae."In: Flora of 
China. Wu, C. Y., Ranven, P. H., et al., Science Press: Beijing, China, Vol.15 (1996):329-337.

6. Liu, Q., Gong, Y.S., Chen, X., et al. "Analysis on the orthogonal experiment of cutting propagation of four Buddleja davidii breeding lines."Guangdong Agriculture Sciences 11(2008):32-34.

7. Shi, C. J., and Liu, H. M. "The Influence of Native Plant on Urban Landscape Construction."Xiandai Horticulture4(2013):101-102.

8. Tallent-Halsell, N. G., and Watt, M. S. "The Invasive Buddleja davidii, (Butterfly Bush)."Botanical Review75.3(2009):292-325.
9. Wilson, S. B., Thetford, M., Mecca, L. K., et al. "Evaluation of 14 Butterfly Bush Taxa Grown in Western and Southern Florida: I. Visual Quality, Growth, and Development."Horttechnology 14.4(2004):605-612.

10. Xu, L. "Effects of Different Substrate and Different Rooting Agent for Buddleja Rooting Cuttings." Anhui Agricultural Science Bulletin21.5(2015):15-15.

11. Zhang, Y. M., Yan, Y. Y., Cao, W. X., et al. " The effect of different substrates on the Cuttage Propagation of Buddleja."Journal of Green Science and Technology15(2017). 